\title{
NATURALEZA Y GRAFÍA. EL CORPUS DOCUMENTAL DE LAS COLECCIONES ANIMALES EN EL REAL GABINETE DE MADRID, 1752-1790 ${ }^{1}$
}

\author{
María Eugenia Constantino \\ Instituto de Historia - CSIC \\ maru.cons@gmail.com
}

Recibido: 19 junio 2014; Aceptado: 20 octubre 2014.

Cómo citar este artículo/Citation: Constantino, María Eugenia (2015), "Naturaleza y grafía. El corpus documental de las colecciones animales en el Real Gabinete de Madrid, 1752-1790”, Asclepio, 67 (2): p110. doi: http://dx.doi.org/10.3989/asclepio.2015.28

RESUMEN: En 1776, Pedro Franco Dávila, director del Real Gabinete de Historia Natural en Madrid, implementó una estrategia de adquisición de ejemplares naturales para ampliar las colecciones monárquicas. En ella involucró a corresponsales, expedicionarios, eruditos y aficionados en América y Europa que debían enviar remesas de producciones naturales asociadas a una serie de índices e inventarios que documentaban los envíos y permitían controlar su tránsito hasta Madrid. Este artículo explora el corpus documental generado alrededor de las colecciones de historia natural enviadas al Real Gabinete de Madrid y busca analizar su dimensión instrumental como herramientas indispensables para registrar y estabilizar la información sobre los diversos procesos, prácticas y actores implicados en el coleccionismo y la producción de conocimientos sobre la naturaleza.

PALABRAS CLAVE: Gabinete; Inventarios; Coleccionismo; Pedro Franco Dávila; Historia natural.

\section{NATURE AND GRAFIA. THE ANIMAL COLLECTIONS' DOCUMENTARY CORPUS IN THE ROYAL CABINET OF MADRID, 1752-1790}

ABSTRACT: In 1776, a strategy to acquire and increase the number of specimens in the collections of the Royal Cabinet of Natural History in Madrid was implemented by its director, Pedro Franco Dávila. The plan that involved correspondents, expeditionaries, savants and amateurs in America and Europe, asked for the sending of consignments of natural products usually associated to a series of indexes and inventories that documented the shipments, and allowed the control of their transit to Madrid. This article explores the documentary corpus generated around the collections of natural history sent to the Royal Cabinet of Natural History of Madrid, and searches for the analysis of its instrumental dimension as indispensable tools for the registration and stabilization of information about the diverse processes, practices and actors implied in nature's collecting and knowledge production.

KEY WORDS: Cabinet; Inventories; Collecting; Pedro Franco Dávila; Natural History.

Copyright: $\odot 2015$ CSIC. Este es un artículo de acceso abierto distribuido bajo los términos de la licencia Creative Commons Attribution-Non Commercial (by-nc) Spain 3.0. 
Hay relaciones entre el gran almacén y el museo, entre las cuales el bazar es el eslabón intermedio. La acumulación de obras de arte en el museo se asemeja a la de las mercancías allí donde, al ofrecérsele masivamente al paseante, despiertan en él la idea de que también tendría que corresponderle una parte.

Walter Benjamin, El libro de los pasajes.

Museo y almacén es una analogía que se repite con frecuencia cuando se observan con detenimiento algunas de las prácticas asociadas a uno y otro espacio. Incluso si lo miramos superficialmente, no es gratuito ni inocente que la asociación de ambas acumulaciones de objetos se presente en nuestra mente cuando pensamos que tales objetos comparten, como dice Benjamin, el estatuto de mercancías en tanto bienes de consumo cultural o comercial. Ahora bien, si vamos más allá y pensamos en las prácticas que se dan al interior de ambos espacios, veremos que contabilizar, describir, clasificar y supervisar son actividades compartidas que generan un corpus documental vinculado a la necesidad de controlar aquello que entra, sale, circula o se conserva almacenado o en su caso, expuesto. En su dimensión práctica, que es la que lo origina, el corpus, formado por listas, descripciones e inventarios, tiene como finalidad estabilizar la información sobre los movimientos realizados alrededor de una colección. Sin embargo, en una dimensión más bien teórica, los documentos del coleccionismo también pueden interpretarse como instrumentos de visibilización de lugares, personas, prácticas y procesos soslayados historiográficamente, o bien, como herramientas útiles para fabricar conocimiento fiable y dar fluidez a la comunicación entre las distintas comunidades científicas, como mediadores entre los distintos usuarios de una comunidad epistémica, o como intermediarios que muestran cómo entran en contacto e interactúan distintos regímenes de conocimiento (Schaffer, 2011, p. 285). Lo cual les confiere una dimensión instrumental asociada a lo que en algún momento se ha llamado «Tecnologías de papel» (Hess y Mendelsohn, 2010, p. 287; Müller-Wille y Charmantier, 2012, p. 743)2.

En el Real Gabinete de Madrid y sus colecciones de historia natural, que es el tema que enmarca este artículo, la documentación fue tan importante como los objetos mismos, pues las producciones naturales colectadas viajaban por mar y tierra sin la certeza de que llegarían en buenas condiciones a destino, lo cual implicaba que solo a través de la observación de las descripciones, clasificaciones y dibujos habría una po- sibilidad de (re)conocer y completar, en lo posible, al ejemplar y las pérdidas que pudiera sufrir ${ }^{3}$. Las inminentes contingencias provocadas por el tránsito de la naturaleza entre su lugar de origen y los puertos de llegada en Europa hacían indispensable la producción de inventarios: una práctica propia de navegantes, viajeros y comerciantes que requerían de herramientas para controlar la circulación de objetos y mercancías, y que había sido adoptada por los naturalistas al enfrentar el reto de movilizar ejemplares para los gabinetes. Un hecho que provocó que los inventarios migraran del área comercial a la intelectual, transformándose en instrumentos teóricos susceptibles de confrontar el conocimiento europeo sobre la naturaleza colonial con lo que en realidad se encontraba en los territorios explorados, además de una eficaz forma de retroalimentación ${ }^{4}$.

Los catálogos e inventarios de las remesas permitían un primer nivel de lectura, donde los lectores (usualmente los transportistas, y ciertamente, los destinatarios) podían obtener la información sintética del envío, basada en cifras y nombres. Sin embargo la mirada analítica del coleccionista, habitualmente dirigida por preguntas específicas, permitía ir más allá para rescatar un conocimiento que cartografiaba el terreno y sus producciones, tanto como a los actores participantes en la red de adquisición de piezas. Lo cual daba a las notas de remisión el carácter de mediadores entre distintos grupos de personas, y entre personas y grupos de objetos, mientras adquirían una plasticidad que ahora se considera como uno de sus principales atributos en cuanto herramientas epistémicas útiles para generar problemas de investigación ${ }^{5}$. El potencial epistémico de los inventarios, emerge cuando tratamos de descubrir las diferentes capas de conocimientos, prácticas, procesos y actores que se esconden debajo de sus letras y números. Un acto que implica un proceso de revelación en el que James Delbourgo y Staffan Müller-Wille (2012, p.710) nos piden observar a las prácticas de producción, porque ello nos permitirá vislumbrar cómo los ejercicios de escritura asociados a la ciencia, la administración y el comercio se amalgamaron para contribuir con el esfuerzo de reorganizar la labor científica, organizar los contenidos del mundo y registrar los procesos por los cuales se conocía y describía su contenido. Prácticas que habría que apreciar como intrínsecas y permanentes del ejercicio de naturalistas y coleccionistas de producciones naturales ${ }^{6}$.

La documentación que resultaba de esas prácticas contenía visiones espaciales y temporales de la naturaleza, registraba prácticas relacionadas con proce- 
sos de intercambio y colección de objetos, mostraba ejercicios vinculados al reconocimiento social y se usaba como medio de difusión (o de presentación) de las identidades de los científicos (Delbourgo y Müller-Wille, 2012, p. 710), no obstante que la escritura de los naturalistas de gabinete fuera distinta de la de aquellos que recolectaban u observaban directamente en el campo; diferencia que al final resultó evidente en las circulares, misivas e instrucciones que desde la Corte se expedían para solicitar piezas para el Real Gabinete de Madrid, tanto como las notas e inventarios que los corresponsales remitían desde el campo con los objetos.

Los documentos cortesanos contenían una percepción de la naturaleza sustentada en los libros de historia natural, pero también influenciada por relatos de viajeros, navegantes y comerciantes que, por diversas razones, fabulaban o repetían dislates heredados de sus antecesores (Pimentel, 2003a, p. 47). Lo cual, en una comunidad científica preocupada por la precisión, la verdad y la razón, obligaba al destierro de errores, la confirmación de verdades a medias o, simplemente, la observación de lo desconocido, buscando evidencia material que ayudara a confrontar lo ya sabido con lo recién encontrado. En ese esfuerzo se insertaba, sin duda, la conformación de colecciones para el Real Gabinete de Historia Natural de Madrid.

\section{EXPECTATIVAS DE ULTRAMAR}

La iniciativa de crear una colección monárquica de historia natural tuvo un primer antecedente en 1752, cuando el marino Antonio de Ulloa mandó a las provincias y virreinatos hispanos una circular que solicitaba el envío de minerales y piedras preciosas para conformar el Real Gabinete de Minas ${ }^{7}$. La solicitud, que se insertaba en la tradición de documentos normativos enviados por la Corona española para recopilar información de sus virreinatos, buscaba que los habitantes remitieran cualquier mineral digno pertenecer a una colección monárquica, no obstante que en sus líneas no se especificara con claridad el tipo de minerales requeridos ni las características de la documentación que debía acompañarlos. Lo cual, tuvo como resultado que los habitantes de los virreinatos respondieran con objetos tan variados como plantas, semillas, «una concha con dos perlas», ${ }^{8}$ "una piedra de cobre virgen de extraordinario peso y tamaño $»^{9} \mathrm{o}$ "siete piedras de plata ${ }^{10}$ que a lo sumo estaban documentadas por alguna nota que especificaba el nombre del remitente, el lugar de procedencia, su nomenclatura local y una sucinta descripción del objeto. Datos que en su mo- mento no eran suficientes para hacer una verdadera historia natural de los ejemplares pero que, por el contrario, resultaron relevantes para el conocimiento del potencial del territorio al cual pertenecían, tanto como para diseñar una segunda estrategia de acopio más clara y consecuente con los objetivos de una colección imperial| ${ }^{11}$.

La segunda iniciativa surgió después de que, en 1771, la Corona adquiriera el acervo conformado por el guayaquileño afincado en París, Pedro Franco Dávila, quien al ser nombrado director de la institución enfrentó la consigna de conformar para el Gabinete Real una verdadera colección monárquica que visibilizara el potencial natural de la Corona. El mandato requería de estrategias diseñadas para motivar la participación de los habitantes en territorios hispanos y extranjeros, y eso llevó a Dávila a emprender una estrategia de adquisición de ejemplares basada en la redacción y difusión de un documento normativo que funcionara para involucrar a una gran cantidad de personas (aficionados, especialistas, eruditos y legos) en la formación del Gabinete. El resultado fue la Instrucción Circular $^{12}$ (véase imagen 1).

La Instrucción diseñada por Dávila como elemento protagonista de su estrategia de acopio apareció publicada en España por primera vez en las páginas del Mercurio Histórico y Político de Madrid de mayo de $1776^{13} y$, para asegurar un mayor alcance, fue enviada un mes después a las provincias, virreinatos e intendencias hispanos bajo el formato de un cuadernillo de veinticuatro páginas impreso por ambas caras. Su contenido era un reflejo del conocimiento que a través de los años Dávila había adquirido como resultado de la correspondencia con sus pares y el intercambio con aficionados, tanto como de la lectura de libros de historia natural e informes sobre la naturaleza europea y colonial. Lo cual era indispensable para saber con acierto y pedir con precisión el tipo de ejemplares que requería para sus colecciones; eso incluía desde especificar el nombre ordinario, las características y la ubicación geográfica de los ejemplares, hasta explicar los métodos para conservarlos y la forma de remitirlos al Real Gabinete.

Cada apartado de la Instrucción separaba y agrupaba por semejanza las producciones naturales de acuerdo con los cánones de la historia natural contemporánea. Había una sección para el Reino Mineral, con sus respectivas «Tierras, Piedras, Minas, Sales y Betunes», otra para el Reino Animal, separado a su vez en cuadrúpedos, pájaros, insectos, reptiles, peces y conchas, y la última dedicada al Reino Vege- 
tal, subdivido en petrificaciones. Un apartado distinto solicitaba curiosidades del arte, específicamente «vestidos, armas, instrumentos, muebles, máquinas, ídolos y otras cosas de que usaron los Antiguos Indios, u otras Naciones». Mientras que el apartado final, titulado «Modo de preparar y enviar todo lo que se pide» era un manual de métodos de conservación y embalaje ${ }^{14}$.

El texto, que comienza enunciando las producciones minerales solicitadas, se lee desde el inicio como una larga lista de formato horizontal que menciona, casi en su totalidad, el mundo conocido de las piedras, las minas, las tierras, las sales y los betunes. Líneas como éstas "Las Tierras y Arenas son de diferentes colores, como blancas, negras, rojas, amarillas, azules, etc. Unas son puras, otras mixtas con ocres, con sales, azufres o betunes, con partes animales y vegetales, con polvos o pajitas de oro, etc. ${ }^{15}$ enlistaban en lo posible toda la taxonomía asignada a los especímenes requeridos por Dávila, no obstante que en la Instrucción el reino mineral se redujera sólo a tres páginas.

Contrario a lo que sucedía con los minerales, el reino de los animales aparecía más profuso que el anterior, y desplegaba en sus líneas una mayor cantidad y variedad de características, detalles particulares y lugares de origen. El inventario se enriquecía en ese apartado con descripciones minuciosas de lo que se esperaba recibir, pues Dávila tenía la expectativa de que los lectores de la Instrucción le corresponderían al pie de la letra con sus encargos, lo cual era una variable que le obligaba a proveer la mayor cantidad de información posible si en verdad quería cumplir sus expectativas. Esta minuciosidad se veía en ejemplares como el "Oso hormiguero de México», al cual Dávila enfatizaba que era «llamado por los Indios Izquiepat/»; o en "otra Ardilla muy rara de Nueva España» que el naturalista explicaba que tenía "pintas blancas sobre un color gris, que tiene la cola abierta o partida en cuatro colas, que parecen otras tantas ramas que salen de un tronco» ${ }^{16}$.

Los párrafos descriptivos, aunados a sus nombres autóctonos y coloquiales tenían como objetivo prefigurar en la mente de los lectores, la imagen de los animales solicitados. Lo cual era necesario e indispensable si consideramos que los destinatarios de la instrucción poco o nada tenían que ver con su autor, que podían conocer los especímenes con nombres distintos, o que podían ser tan ignorantes como conocedores de la historia natural europea. Variables que al final prefiguraban un lector heterogéneo y anónimo que muy probablemente ignoraría los nombres en latín o los sistemas taxonómicos al uso en Europa, tal y como explicaba Dávila en una nota al pie de la primera página ${ }^{17}$. Pero las peticiones del director del gabinete, aunque eruditas, no siempre correspondían con la realidad y, en algunos casos, incluso pudieron haber contribuido a distorsionar o desviar la búsqueda. Esto podemos verlo en tres ejemplos: las serpientes bicéfalas que Dávila pensaba no como monstruosidades sino como una especie propia de las costas de Malabar por el hecho de haberse conocido más de un ejemplar y por encontrarse descritas en las historias naturales de Aldrovandi y Seba; los cucuyos, insectos americanos que deseaba con especial interés porque había tenido noticia de "la luz tan clara y durable que despiden sus ojos en la oscuridad», de la cual se valían los nativos para iluminar sus aposentos permanentemente, «pues se ve alternativamente que cuando unos ocultan la luz, otros la manifiestan»; y el «Perro volador que se encuentra en la América Austral», del cual se decía que tenía «desde la cabeza hasta la extremidad del cuerpo una membrana extendida de ambos lados con la que vuela» ${ }^{18}$.

Con los casos anteriores se puede inferir que parte de la naturaleza descrita en la Instrucción era, probablemente, un producto de los relatos de viajeros y no de la propia experiencia del naturalista, lo cual terminaba ayudando a difundir creencias comunes, aunque quizá, poco veraces, sobre lo que podía encontrarse en los territorios de ultramar. Esto podría ser claro en el ejemplo del «Perro volador» que bien podía tratarse de un animal imaginario o bien de uno real que, al ser descrito solamente por palabras y sin referentes materiales o un nombre genérico que lo significara, derivó en el ser descrito que incluso puede imaginarse como un ente fantástico ${ }^{19}$. De ahí que la necesidad de descartar o aprobar esas creencias permaneciera latente en la mente de los naturalistas, que buscaban en los animales naturalizados la prueba de confirmación de su existencia. En consecuencia parecería que, Dávila, además de buscar el aumento per se de las colecciones, buscaba también contribuir al mundo de la historia natural con la evidencia material de aquello que sabía que existía en algún lugar del territorio español. No obstante, si pedir y esperar la llegada de animales extraordinarios para aprobar y validar un conocimiento del cual se dudaba era una de las prerrogativas del director de un Gabinete monárquico, lo que se encontrara y enviara en respuesta a estas solicitudes fue el privilegio de sus corresponsales y recolectores, y eso se configuró como una variable definitiva en el proceso. 
Imagen 1. Nómina hecha de orden del Rey Nuestro Señor, por Dn. Pedro Franco Dávila Director del Real Gabinete de Historia Natural. AMNCN. Catálogo de documentos del Real Gabinete de Historia Natural (1752-1786). Ref. 276

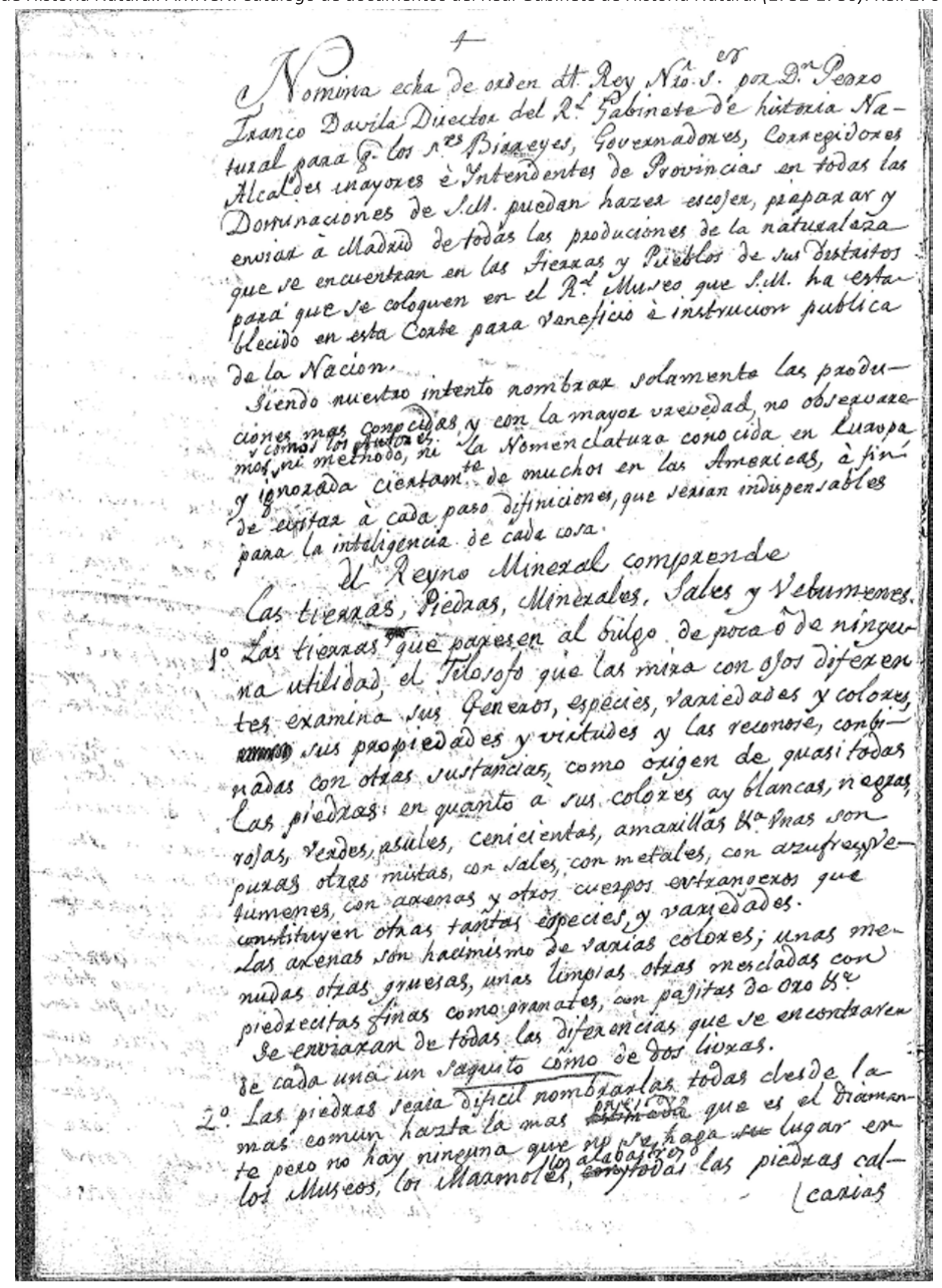




\section{CORRESPONSALES Y RECOLECTORES}

Al estar en distintos puntos geográficos y tener contacto directo con la naturaleza, los corresponsales se enfrentaban a un mundo que poco o nada tenía que ver con el que desde la Corte prefiguraba Pedro Franco Dávila en su Instrucción. Como naturalista de gabinete, su mundo estaba circunscrito a las paredes que resguardaban la colección y, de cierto modo, a él también. Su trabajo residía en actos de gestión, reflexión, lectura, escritura y observación pausada, llevados a cabo en un ambiente cerrado, controlado y protegido lejano del campo que enmarcaba el trabajo de los corresponsales, quienes, por su parte, debían enfrentar las contingencias del mundo natural: lluvias, cambios climáticos, ataques de insectos, enfermedades, recorridos accidentados por lugares inhóspitos y demás situaciones propias de quien viaja y se adentra en la naturaleza.

En su devenir, los corresponsales, que podían o no ser también recolectores, observaban, conseguían, acopiaban y documentaban ejemplares con la presión de un tiempo dividido en tres momentos: buscar y cazar al animal; conservarlo de la mejor manera para que soportara el tránsito de varios meses hasta llegar a Madrid sin perder sus atributos físicos; nombrarlo y describirlo ${ }^{20}$. Procesos que implicaban pericia y habilidad, pero que también requerían estrategia, inteligencia y visión; cualidades necesarias para reconocer la naturaleza que salía a su paso contrastándola con aquello que encontraban escrito en las solicitudes monárquicas.

La cantidad de variables implícitas en las prácticas de conformación de la colección monárquica era grande, y esto afectaba especialmente a los corresponsales, que pocas veces -o ninguna-podían asegurar que el ejemplar colectado Ilegara con las cualidades que esperaba el director del Gabinete, es decir, bien conservados, completos y con el menor deterioro posible. Los fracasos en los métodos de conservación, los accidentes sucedidos durante la cacería y los malos manejos de las remisiones eran cuestiones que incidían y afectaban el buen estado de los ejemplares, y que, ciertamente, repercutían en el prestigio del corresponsal. Por ello, quien realizaba el proceso de localizar, capturar y preparar debía, además, producir una documentación que sirviera no sólo para controlar el tránsito de los ejemplares, sino también para demostrar su trabajo, validar su conocimiento y justificar cualquier desperfecto del que no fuera directamente responsable. Con esa finalidad surgieron los índices y catálogos o inventa- rios que enlistaban y describían el contenido de las remesas enviadas al Real Gabinete.

En España uno de los principales corresponsales de Dávila fue Cristóbal Vilella, pintor aficionado a la historia natural y residente en Palma de Mallorca que, desde 1773, enviaba importantes remesas de aves y peces principalmente. Con ellas contribuyó en gran medida al reconocimiento de la naturaleza de las Islas Baleares, mientras daba cuenta de las prácticas y los procesos que había llevado a cabo para conformar y conservar sus ejemplares ${ }^{21}$.

En abril de 1778, dos años después de la emisión de la Instrucción Circular, Vilella envió a Madrid una remesa de nueve cajones con diversas piezas acompañadas de un extenso inventario que estaba hecho para describir más que para nombrar ejemplares. En sus listas, el pintor numeraba y designaba los ejemplares por su nombre común, lo cual correspondía con el estilo de muchos otros naturalistas que por comodidad, ignorancia o falta de tiempo permanecían al margen de los problemas que la insuficiencia de los sistemas de clasificación al uso provocaba entre los naturalistas eruditos. Sus descripciones se quedaban en el terreno de lo coloquial y tampoco configuraban problemas más complejos que informar acerca de los detalles necesarios para hacer una breve historia del ejemplar. Las características morfológicas externas, los hábitos alimenticios, la forma de vida y el potencial utilitario de los ejemplares era lo que generalmente se decía sobre ellos, y quizá con eso bastaba para que en el Gabinete Real se les clasificara y ordenara en el sitio que les correspondía.

Por ejemplo, un macho cabrito, conocido en la isla como "Boch», era enviado con varias aves en el cajón número cuatro de esa remesa. Vilella lo describía como un animal de color negro, de pelo raso, «con pintas blancas de barba larga», que se había "criado casero en la Villa de Santanyi, distante siete leguas de esta Capital [la de Mallorca]», y que había disecado «persuadido que tal vez en el R. Gabinete aún no lo tendrían y por ser bien conservado». Sobre sus virtudes mencionaba que era comestible y que su carne la vendían «en la carnicería todos días, como y también la de vaca, carnero, oveja y cabra», y que "todas las guardas o manadas de cabras tienen dos machos cabritos de igual tamaño por servir de padres» ${ }^{22}$.

En sus descripciones, el pintor-corresponsal nunca aludía a los autores paradigmáticos de la historia natural y evitaba en todos los casos usar los sistemas de clasificación habituales, mientras que los aspec- 
tos que resaltaba y validaba sin dudar eran su habilidad como gestor y recolector de ejemplares, más su práctica como disecador. Esto se hacía evidente cuando explicaba los medios por los que había obtenido un animal y justificaba las circunstancias ajenas a él que en todo caso podrían afectar el buen estado de conservación de la colección. Un ejemplo de ello era el número dos del mismo cuarto cajón: un buitre o voltó -en mallorquín-, descrito por Vilella como «el ave más grande de las de Rapiña que se crían en esta Isla», y que medía "de un cavo de ala al otro diez y siete [sic] palmos Mallorquines», tenía «el pico muy fuerte y puntiagudo, [y] las uñas fuertes y romas»" ${ }^{23}$. Se criaba en los «Peñascos más escabrosos de esta Isla», tenía la carne negra e inútil como alimento y hacía su nido con varios troncos de gran tamaño. La forma en que lo había obtenido se explicaba en un par de líneas, donde el corresponsal enunciaba que el animal había llegado vivo a sus manos después de que un cazador lo encontrara en un arenal donde desollaban ganado, y le disparara «con escopeta, con bala, y ocho postas» rompiéndole el "hueso maestro de una ala ${ }^{24}$. Lo cual era una información que, aunque breve, explicaba tres cosas: una, que para conseguir el ejemplar Vilella se había valido de un tercer recolector que en este caso era un cazador, pero que podía haber sido también un pescador o un buzo, como explicó en algún otro caso; dos, que ese recolector había cazado al animal sin preocuparse por lastimarlo demasiado, esto significaba que el cazador no tenía el sentido estético, científico y analítico necesarios para pensar en que un animal destinado a la investigación, la naturalización y la colección debía permanecer lo menos lastimado e incompleto posible; ${ }^{25}$ tres, que cualquier desperfecto en el ala no era su responsabilidad, o había sucedido antes de su posesión, lo cual lo exoneraba de cualquier acusación de brutalidad o descuido que pudiera denunciarse sobre el mal estado de las piezas. En pocas palabras, el naturalista estaba dando cuenta de los actores y las acciones implicados en un primer paso del proceso de acopio de colecciones, pero también estaba manifestando entre líneas aquello de lo que él era o no responsable para justificar su crédito como naturalista.

El formato del inventario de Vilella seguía en partes el ejemplo de la Instrucción de Dávila, ya fuera al usar los nombres comunes o al ocuparse de mostrar una cartografía que ubicaba ejemplares útiles en lugares que podían situarse como potenciales fuentes de recursos naturales. El diálogo entre los escritos de ambos naturalistas se completaba cuando Vilella re- portaba a Dávila su práctica en los métodos de conservación. Un proceso en el que tenía participación directa y se destacaba, pues era reconocido como un buen disecador debido, en parte, a su formación como pintor anatómico. En su inventario, el pintor hacía explícito el haber aplicado los métodos de preservación de ejemplares prescritos en la Instrucción y afirmaba haber seguido las indicaciones en cuanto al uso de polvos y barnices recomendados por el director del Gabinete ${ }^{26}$. Sin embargo, también explicaba sus percances, pues peces como la «musola» habían sido difíciles de disecar por «tener mucha carne gorda, con huesos fuertes y duros ${ }^{27}$.

El problema de la conservación de ejemplares que aparecía en los inventarios de Vilella era uno de los temas de preocupación y ocupación entre naturalistas, corresponsales y recolectores, y desde ambos lados del Atlántico se manifestaba como uno de los factores decisivos para el envío de ejemplares. Desde Nueva España, por ejemplo, la queja era similar. Josef de Ibargoyen, Contador de Tabacos en la provincia de Guadalajara y corresponsal desde el virreinato, declaraba en el inventario que escribió para documentar la remesa de 13 cajones con producciones naturales, que no tenía «dificultad en adquirir animales particulares, pero [que] no hay quien sepa desecarlos», y que los poco expertos disecadores que había encontrado, apenas habían podido preparar un par de aves -alcatraces-, que mandaba aunque no duraran lo suficiente para soportar el traslado a Madrid ${ }^{28}$.

La remesa que Ibargoyen remitía al Gabinete Real en julio de 1783 respondía como la de Vilella al llamado que Dávila había emitido siete años antes, ${ }^{29}$ y las coincidencias entre los inventarios de ambas eran evidentes: tanto el novohispano como el mallorquín enumeraban sus ejemplares y los llamaban con nombres autóctonos, cartografiaban especímenes, daban cuenta de su práctica y mostraban la red de actores involucrados en el proceso de recolección.

En su inventario, Ibargoyen mostraba lo que a sus ojos era tan valioso, extraordinario y curioso, como para ser coleccionado en el Gabinete Real: piedras de plata y oro, cristalizaciones, minerales, piedras bezoares, mariposas, "excremento de caimán», "huesos de gigantes», conchas, caracoles, raíces y maderas petrificadas que en conjunto pretendían mostrar un fragmento de lo que podría llamarse naturaleza novohispana (veánse imágenes 2 y 3). Así, Zacatecas, Tapalpa, Guanajuato, Coahuila, Sonora, Sayula, Guadalajara, Colima y varias otras regiones del norte de lo que hoy se conoce como México, se configuraban 
Imágenes 2 y 3. Relación de las curiosidades que remite el Excelentísimo Señor Don Matías de Gálvez Virrey de Nueva España para el Real Gabinete de Historia Natural de Madrid que le dirigió de la Provincia de Guadalajara en aquel Reino el Contador de Tabacos Don Josef Ibargoyen. AMNCN. Catálogo de documentos del Real Gabinete de Historia Natural (1752-1786). Ref. 792

S.

(Pelacion De las curiosidades que remine d Esino señor

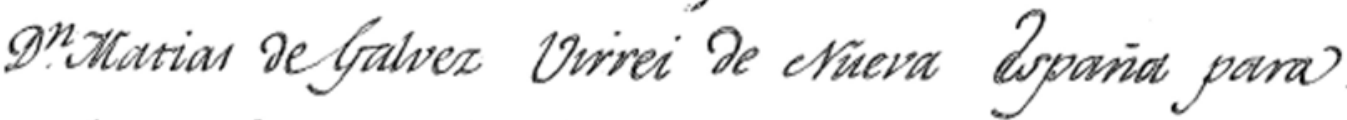
el Beal Gavinere de Historia crammat de chadrio que

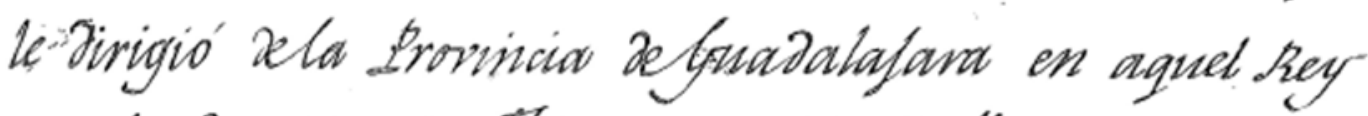
no el Comador de Labuws Dn Toref Margoyen.

Cason mop?

+ Comiene piedras de plara de los cximenales de Tacarecan, Botasios. Pames y Batopilan en las Sonon: van separadan y.con in correspondien. te rotulo las de cada porre.

Incluye ademan piedran de on delan cwi. nan del Tesgniral, Sierra de Pinos y Tapalpas. Los granos d'porticular de oro de su supenficie se hacen man manifiestan, molandose las pieDras con aqua.

a.r

Carom mor.

T

Comiene contexos y ravices del ctrbol de táals samio que hai en la suira de phonosan y unou pieran a' nomera. De Ramas o' Conchas? 
que parrecen arrificiales, que suclen nocer como las roma de algunos ctrboles de los que Llaman Mesquines.

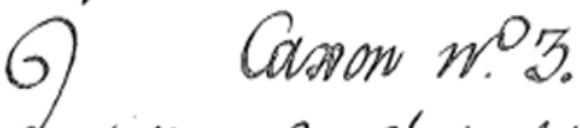

Costa' Heno de Chmistahiaciones especialles

- espraidas de las etimas de Plara de Guanafuato.

\section{Cason mis:}

Una piedra Imán cahada de peso de ca. torre libras de min buena calidad: es delas Prorincia de Coahnila.

- Una tablera y un pedarso de una especie de piemst negra mi compacia y hustrosa que llaman Istere. Se halla en varias partes.

- Una vola de piedma neigra, que la persoma que la trafo de Sonora aseguna haberse sa. cado en aguella Provincia del vienne de) in Burey, añatiendo no ser la inicas de? esta erpecie que se ha hallado denoro de semer 
como regiones fértiles e incluso productoras de algunas monstruosidades y animales extraordinarios cuyo registro contribuía de algún modo con alguna de las varias fabulaciones que Dávila había plasmado en su texto. Junto al «becerrito monstruoso de dos cabezas" y el "corderito de dos cabezas, seis pies y dos colas que estaba cubierto de lana y se la comió la polilla», ${ }^{30}$ Ibargoyen enviaba también

La piel rellena de un animal que unos cazadores mataron pocos meses ha en un cerro inmediato a Cocula. Dicen no haberse visto otro semejante; que tenía hocico largo y delgado, los dientes agudos, los ojos muy pequeños y redondos, y las uñas corvas y envainadas; que su carrera era poco veloz, y que perseguido por perros se volvía con furor para morderlos; añaden que su carne olía a pez o marisco. ${ }^{31}$

La pieza que evidenciaba la existencia de ese ejemplar raro llegaba, según decía una nota a bando, «muy maltratada [y] sin piel»32. Lo cual evidenciaba el deterioro que los viajes causaban, mientras explicaba cómo el inventario llegaba sin un referente físico adecuado que materializara las palabras que dibujaban un animal que podría haber sido más o menos grande, feroz o fantástico. El texto, que es tan descriptivo como un cuento, también narra una escena de caza en la que hay un contexto (actores, acciones y el uso de otros sentidos complementarios a la vista) que difería de los cánones de escritura encontrados en los libros de historia natural. Un recurso que también Vilella usó al describir las cualidades de algunos ejemplares, como por ejemplo el Águila de mar, cuya carne no se comía por tener "sabor de marisco", o las condiciones de caza de un ave llamada "Corp» de la especie de los grajos, a quien un cazador mató con una escopeta después de esconderse en un hoyo cubierto de algas al que le hizo una abertura para poder apuntar y disparar al ave ${ }^{33}$.

Los inventarios de Vilella e Ibargoyen ciertamente tenían un estilo de escritura que se alejaba de la erudición sobria de algunos naturalistas europeos, pero no por ello perdían su valor científico. Al dar cuenta de su propia práctica y buscar la validación a su ejercicio como corresponsales, disecadores o naturalistas aficionados, tanto el mallorquín como el novohispano evidenciaron la intervención de actores secundarios que, sabiéndolo o no, también formaron parte de una cultura de coleccionistas: cazadores, pescadores, nativos, teñidores y campesinos que compartían prácticas y saberes incorporados poco a poco en los distintos procesos de selección, recolección y conservación de ejemplares. Pero estos detalles no siempre fueron do- cumentados y, en el caso de algunos expedicionarios, como aquellos en Nueva España, lo que se plasmó en los inventarios que acompañaron sus remesas para el Real Gabinete se vinculó más al mundo de la erudición que al de las prácticas.

\section{ÍNDICES, EXPEDICIONES Y CONSENSOS}

Las expediciones españolas por América y las Filipinas habían iniciado en 1777 como parte de una estrategia monárquica que, entre sus múltiples objetivos políticos, sociales y científicos, tenía el de recopilar información y objetos naturales para el Gabinete Real. Sus miembros, usualmente naturalistas, médicos, cirujanos, pintores y botánicos reconocidos, remitían sus hallazgos a Madrid con toda la frecuencia que les fuera posible. En Nueva España, Martín de Sessé, Vicente Cervantes, José Longinos Martínez, Juan del Castillo y Jaime Senseve enviaron, desde marzo de 1789 , remesas de cajones con ejemplares naturales, catálogos y dibujos del virreinato a la península ${ }^{34}$.

El naturalista de la Expedición, José Longinos Martínez, fue el encargado de seleccionar, colectar, conservar, describir y clasificar las colecciones de animales destinadas al Gabinete Real ${ }^{35}$. Su consigna, entre otras cosas, debía cumplir con lo que José Pardo (2012, p.34) ha llamado «el esclarecimiento crítico de la difícil frontera entre lo imaginario y lo real», que era equivalente a erradicar con más contundencia las fabulaciones e ideas erróneas que permanecían en el marco de la historia natural. Con esa premisa, los textos de Martínez y el resto de los expedicionarios debían situarse en el canon de las ciencias naturales y cumplir con el rigor que mandaba la adopción del sistema linneano como eje taxonómico en el Gabinete y el Jardín monárquicos. Esto les llevaría a soslayar, en lo posible, la nomenclatura autóctona para realizar un ejercicio de clasificación en el que se demostrara su conocimiento de todos los sistemas al uso y su correcta aplicación, en caso de que el linneano no fuera suficiente para nombrar los múltiples especímenes novedosos que encontraran.

Las remesas que Martínez expidió para el Real Gabinete estaban documentadas regularmente por lo que él llamaba «nóminas», manuscritos que tenían el formato de listas de números y nombres que correspondían a los animales y dibujos que se hallaban igualmente numerados dentro de los cajones. El índice que el naturalista mandó a José Clavijo desde Cuernavaca el 22 de abril de 1789 registraba una remesa con ejemplares pertenecientes a las categorías de Mammalia y Aves, y se dividía en dos partes ${ }^{36}$. En 
la primera, el naturalista mostraba su conocimiento de los distintos sistemas taxonómicos y nombraba respectivamente a las especies que él consideraba reconocidas de antemano en los textos de Aldrovandi, Linneo, Catesby, Brisson, Klein y Hernández; mientras que en la segunda, los ejemplares enunciados eran los recién descubiertos por él, y sobre ellos proponía una nomenclatura acorde a Linneo y Hernández. Así, términos como "Trochilus Purpureus. Sp. Na.», "Quetzalhoitzitzilin. Hdez. mex. p. 321» o "Anaes Clipoata. Linn. p. 200» identificaban si se trataba de una especie nueva o ya reconocida por los sistemas hernandino y linneano respectivamente ${ }^{37}$.

Las listas, de acuerdo con el método propuesto por Linneo, se podían leer verticalmente, de arriba hacia abajo, pero también, horizontalmente, de izquierda a derecha. La lectura vertical refería los ejemplares, mientras que la horizontal daba cuenta del sistema de clasificación usado y la referencia a la página exacta donde dicho nombre se encontraba.

La remisión hecha en agosto de 1791, por otro lado, incluía un nuevo elemento: el dibujo de cada ejemplar. Un documento más que serviría como referencia en caso de que el animal disecado se perdiera, cambiara su apariencia o simplemente se descompusiera. La aparición de este nuevo instrumento de identificación implicaba un reajuste necesario en la documentación, por lo que la remesa ahora integraba una serie de índices que también debían controlar el tránsito de los dibujos.

A diferencia de la Instrucción de Dávila, que usaba una clasificación aristotélica y taxonomías coloquiales para designar los ejemplares que solicitaba, los inventarios de Martínez mostraban clasificaciones y series de nombres "científicos», normalmente escritos en latín, para referirse a los especímenes de las nóminas. Lo cual era comúnmente entendido como un despliegue de erudición y una forma de validar su autoridad como naturalista. Ya la Instrucción había servido para que Dávila mostrara su saber al enlistar todos los términos autóctonos conocidos, y los inventarios de los corresponsales habían ayudado a exaltar su capacidad como buscadores o conservadores de ejemplares; ahora los índices de Martínez se configuraban como un medio para exponer su conocimiento de los sistemas de clasificación, así como su capacidad para nombrar los ejemplares recién reconocidos en el territorio novohispano. La validación de todos esos conocimientos y capacidades vendría después de que se evaluara lo escrito, se confrontara con lo que de antemano se sabía y se generara un consenso sobre el conocimiento que en todos los casos se manifestaba.

La documentación que acompañaba a los especímenes estabilizaba en palabras la materialidad de los objetos que se desplazaban, pero las mismas palabras, aunadas a los dibujos, consolidaban también los conocimientos tanto como los hallazgos que surgían en el proceso de recolección de ejemplares. Al llegar a su destino, índices e inventarios dejaban de ser una herramienta práctica y de control para transformarse en instrumentos teóricos que desplegaban su dimensión epistémica y completaban un proceso de construcción de saberes sobre la naturaleza desconocida. Si esos saberes alcanzaban la fase final de evaluación y consenso, entonces el proceso tendría como resultado el conocimiento fiable que tanto se buscaba.

La búsqueda de esa fiabilidad conducía, casi inevitablemente, a disputas sustentadas o provocadas con frecuencia por los contenidos de los inventarios. En el caso de los expedicionarios novohispanos, el conflicto surgió alrededor de un índice escrito por Longinos Martínez hacia finales de 1789 para documentar un grupo de aves enviadas al Gabinete de Madrid ${ }^{38}$.

El naturalista había colectado en sus recorridos veinte aves novohispanas desconocidas por los sistemas taxonómicos al uso y, coherente con su quehacer, las había clasificado con una nomenclatura propuesta por él. El expedicionario, así como otros estudiosos y aficionados de Europa y América, había comprobado con el tiempo y la práctica que los sistemas de clasificación eran insuficientes, y en el cumplimiento de sus objetivos debía ajustar e incluso, inventar, nuevas denominaciones para nombrar los ejemplares recién conocidos. Los usos y las costumbres entre expedicionarios dictaban que antes de enviar las remesas a Madrid había que hacer un consenso entre ellos para acordar la clasificación de los ejemplares y obtener la aprobación del director, lo cual garantizaba que aquello que se escribía era correcto. Sin embargo, en esta remesa específica Martínez actuó por su cuenta y remitió las aves sin cumplir con el protocolo ${ }^{39}$. El hecho provocó que el director de la expedición, Martín de Sessé, se sintiera agraviado porque el naturalista había ignorado su autoridad tanto como la «cláusula con acuerdo del Director ${ }^{40}$. En consecuencia mandó, el 13 de agosto de 1791, una misiva a la Corte dirigida al Marqués de Bajamar, pidiéndole que otros especialistas metropolitanos revisaran y corrigieran los inventarios del naturalista, pues su clasificación era arbitraria y poco tenía que ver con los textos que entonces se estaban trabajando. 
Imagen 4. Nómina de algunas aves remitidas al Real Gabinete por la expedición Botánica de N.E. que conviene se examinen por hallarse en cuestión entre el Director y el Naturalista de ella. ARJB. Catálogo de los documentos de la Real Expedición a Nueva España del Archivo del Real Jardín Botánico. Ref. 95.

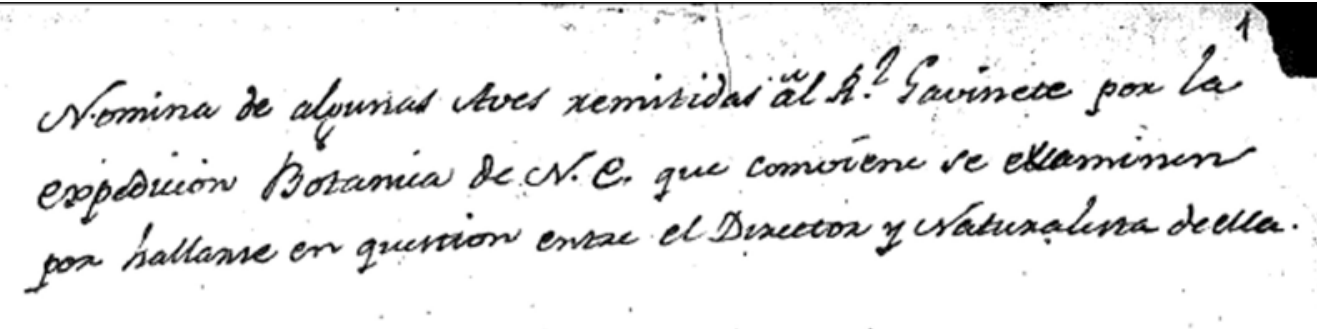

$$
\text { inamalition }
$$

Directón

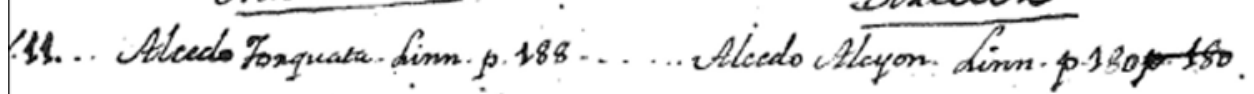

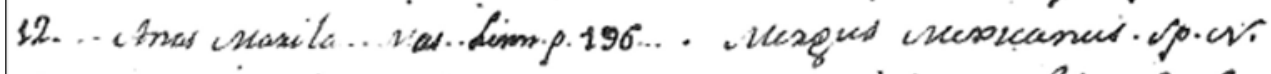

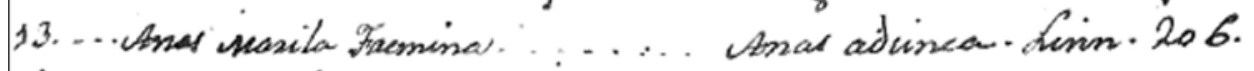

1h... Anar nuspicana... jp.er. .... Anas szrepera. Sum p. 200

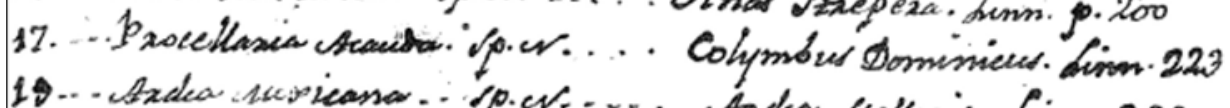

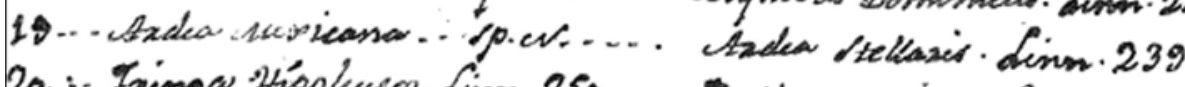

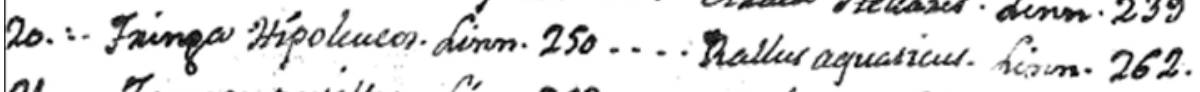

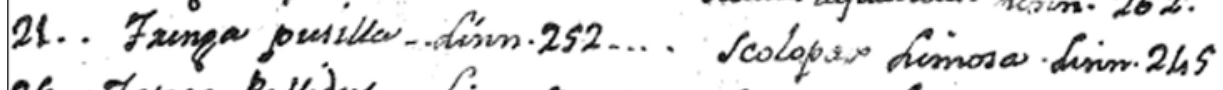

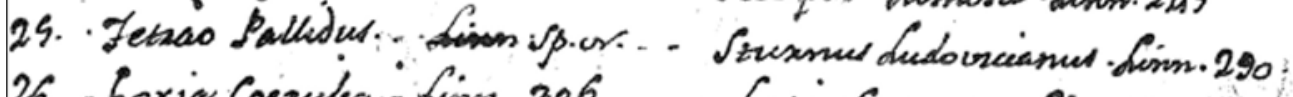

26.. hoxia Coexulea-Sinn 306 ... hoxia Cyanea . dinn 303

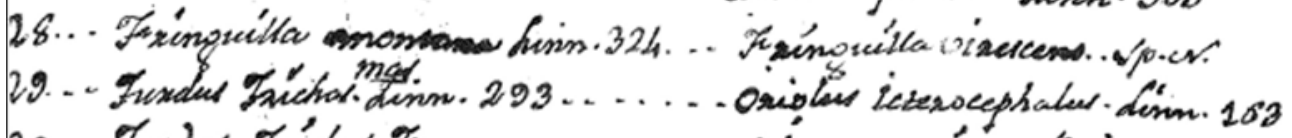

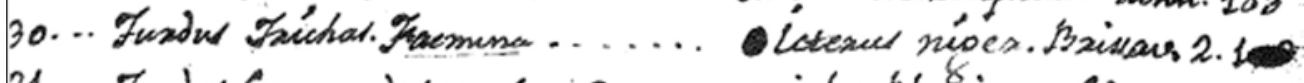

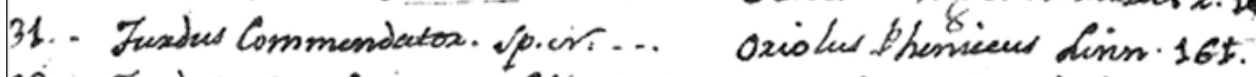

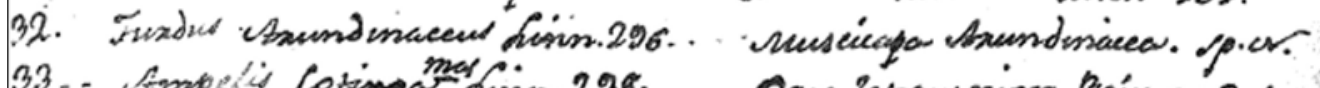

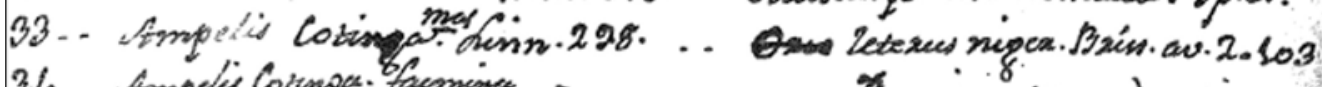

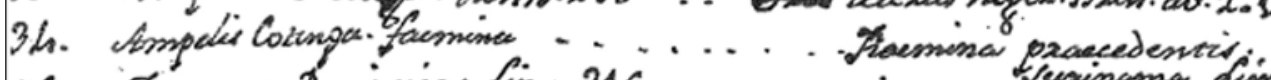

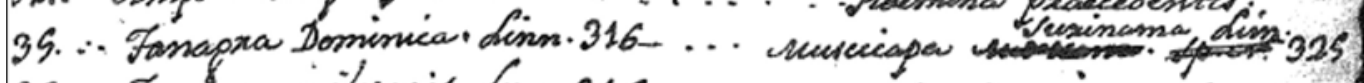

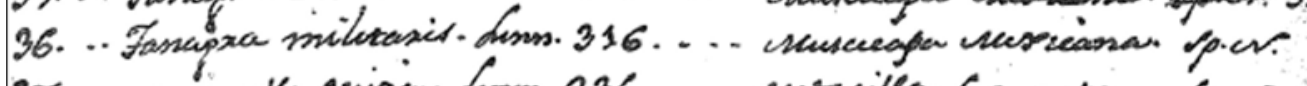

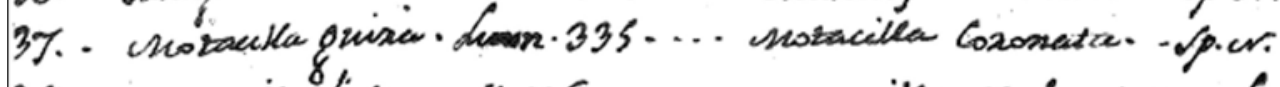

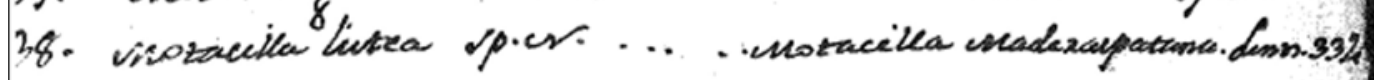

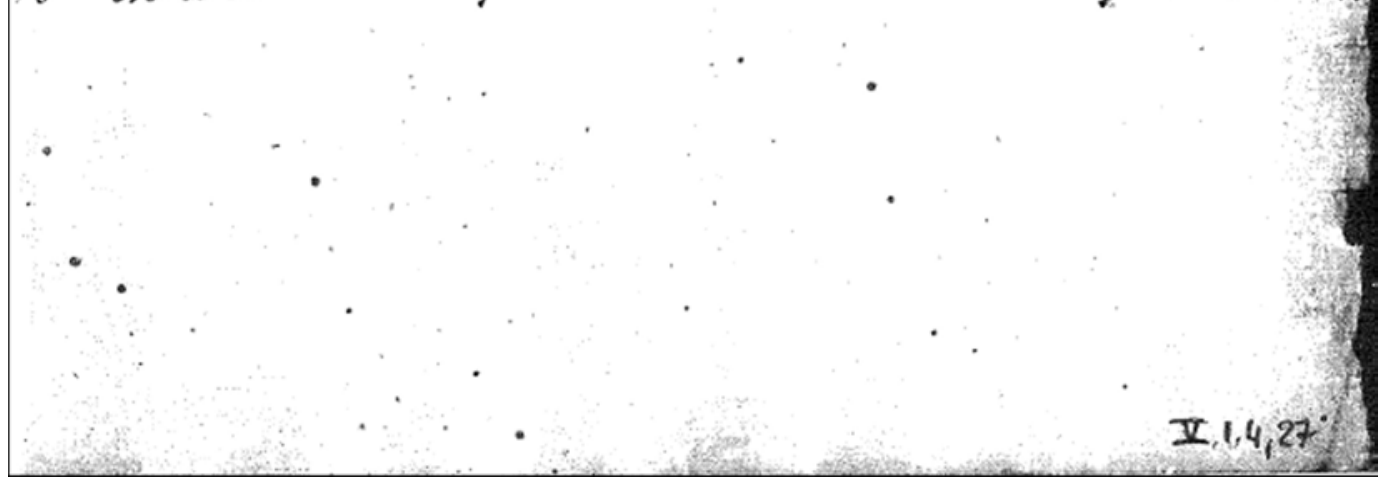


Sessé argumentaba que los dibujos remitidos en el año ochenta y nueve tenían errores y que la denominación que Longinos había hecho de las aves ahí representados era errónea, lo cual representaría, a los ojos de «los inteligentes que pudieran verlas, sin estar instruidos de su capricho», el descrédito de la Expedición. Por eso el director solicitaba que «Personas peritas» examinaran los documentos y le hicieran saber los resultados de su análisis para poder corregir con tiempo los manuscritos, de modo que ni la autoridad de su empleo ni las instrucciones cortesanas se vieran mermadas, pero sí se contrarrestara la «altanería» y la «insurrección» del naturalista ${ }^{41}$.

Anexo a esta carta, Sessé enviaba una lista comparativa donde contrastaba las clasificaciones hechas por ambos contendientes. La nómina (Véase imagen 4) estaba conformada por tres columnas: la primera era numérica y vinculaba los nombres con el espécimen remitido; la segunda era la taxonomía propuesta por el naturalista y la tercera era la nomenclatura corregida por el director. El ideal era que ambas listas se contrastaran con el ejemplar, su dibujo y los libros de historia natural correspondientes para poder así llegar a un consenso y, por ende, a una nomenclatura definitiva. La ventaja, en este caso sería que Sessé tenía los dibujos como referencia para realizar el contraste, aunque esto no significaba que las imágenes representaran con verdad las características necesarias e indispensables para realizar con precisión una clasificación. Llevar esto a cabo era, por consiguiente, más complicado de lo que aquí se dice debido a la incidencia de varios factores. Uno de ellos, y quizá el más importante, residía en el ejemplar mismo.

Consideremos que para realizar la clasificación de un espécimen había que tomar en cuenta todos y cada uno de los rasgos morfológicos que, idealmente, deberían conservarse iguales a cuando el animal estaba vivo para evitar confusiones. Pero esto no era lo usual. Sabemos que algunos ejemplares llegaban después de haber sido cazados por terceros (como los de Vilella e Ibargoyen) y que a otros, como era lógico, no se les podía seguir y observar durante mucho tiempo en su estado natural, lo cual obligaba a los naturalistas a clasificarles después de haberlos matado e incluso, conservado. La posible alteración que afectaría a las características físicas en el paso entre la vida y la muerte era una variable importante, pues la modificación de cualidades como el pelo, los bigotes, las aletas, las plumas y las patas representaba un aspecto sustancial al momento de definir las taxonomías y escribir sus his- torias naturales ${ }^{42}$. Esto, por supuesto, tendría que tomarse en cuenta para evaluar la precisión en la nomenclatura propuesta por los expedicionarios, pues los ejemplares habían sido cazados y remitidos muchos meses antes de la carta de Sessé, y seguramente habrían sufrido pérdidas y variaciones que, no obstante, quizá podrían compensarse si los evaluadores observaban con atención los dibujos que se habían hecho de las aves.

No obstante los esfuerzos de Sessé para dejar claro quién de los dos expedicionarios tenía razón, la verdad es que hasta el día de hoy se ignora el resultado de esta disputa, aunque también es muy probable que no se haya llegado a conclusión alguna. Al final de cuentas, en Madrid tanto como en México, Sessé y Martínez compartieron el crédito por los ejemplares que remitieron a nombre de la expedición, no obstante que al final de este problema terminaron trabajando por separado sin que su mérito como naturalistas se viese afectado. Por otro lado, en el Gabinete Real de Madrid la cantidad de ejemplares que llegaban de los virreinatos y del mismo territorio insular y peninsular superaba las expectativas numéricas, así como al personal que podía encargarse de estudiarlas. Lo cual, aunado a los posteriores problemas políticos sufridos en España en los últimos años del siglo XVIII y principios del siglo XIX, propició que muchos ejemplares se perdieran o permanecieran sin ser reconocidos $y$ clasificados propiamente y que muchos documentos también se perdieran, dejando incompleto o desconocido el trabajo de todos los implicados.

\section{LISTAS QUE VIENEN, LISTAS QUE VAN}

Entre los siglos dieciséis y dieciocho, los naturalistas buscaron comprender y conocer el mundo asignando a las producciones naturales la cualidad de signos, referentes materiales a los que se les designaba un orden y un significado en función de sus características morfológicas. El juego de desciframientos e interpretaciones que implicaba la transformación de un ejemplar en objeto de conocimiento, propició un proceso cognitivo en el que los especímenes sufrieron una metamorfosis que los convirtió en grafías, palabras y nombres que transformaban simbólicamente al complejo mundo natural en un libro. La conversión, como era de esperarse, propició a su vez actos de representación y reconstrucción del mundo natural en los que jardines botánicos y gabinetes de historia natural se configuraron como grandes libreros que exhibían el tan esperado libro abierto de la naturaleza. 
El viraje de la naturaleza a un conjunto de signos le imprimió en su momento una dimensión cultural y social: cada individuo vegetal, animal o mineral pasó a ser un sintagma del paradigma de la naturaleza. Desde cada conjunto se estableció, a manera de sinécdoque, la totalidad del mundo exterior contenida entre las líneas de un inventario, las páginas de un libro o las colecciones de historia natural. En el proceso de visibilización de la naturaleza y significación de las colecciones, la fase de documentación fue un factor esencial que generó prácticas de escritura poco exploradas: desde lo que se ha llamado "escritura de lo cotidiano» (Pardo, 2010, p.32), hasta textos más complejos (libros, catálogos, inventarios) que quizá pudieran considerarse un género dentro de la literatura científica.

Si bien varios historiadores han asumido que la producción de textos, impresos y manuscritos relacionados con la historia natural y sus colecciones era una práctica cotidiana y sistemática asociada al desarrollo de las ciencias, también se ha manifestado la idea de que en ese acto intervenían más factores que el puro interés por el conocimiento. El estudio, la difusión y el desarrollo de las ciencias de la naturaleza fueron aspectos que formaron parte de los proyectos monárquicos para el avance del país y su población. Con la intención de obtener el progreso individual y en consecuencia, el del Estado, desde la Corte española se diseñaron planes y estrategias que buscaron una correspondencia exitosa entre intereses políticos, ciencias y escritura para impulsar la instrucción pública de los habitantes. Una idea que coincidía claramente con el pensamiento de Linneo, quien veía en el estudio de la naturaleza una herramienta para el desarrollo económico de los países.

\section{NOTAS}

1 Este artículo se ha realizado en el contexto de una estancia de investigación posdoctoral en el Instituto de Historia del Centro de Ciencias Humanas y Sociales del Consejo Superior de Investigaciones Científicas, financiada por el CONACYT en su programa de becas a Estancias Posdoctorales y Sabáticas en el Extranjero.

2 En su artículo, Müller-Wille y Charmantier defienden, con base en la antropología de la escritura, el uso de las listas como tecnologías de investigación. Su objeto de estudio son básicamente los inventarios producidos por el naturalista sueco Carlos Linneo. Por su parte, Hess y Mendelsohn miran los documentos producidos en el entorno de la medicina clínica para analizar su potencial como soporte material de información.
El naturalista sueco proponía un método de acopio de información basado en la formación de listas e inventarios que no sólo ayudaban a identificar el orden en la naturaleza, sino que también propiciaban procesos cognitivos sobre quien las escribía tanto como sobre quien las leía y/o estudiaba a profundidad. Según Staffan Müller-Wille e Isabel Charmantier (2012, p.744) el peculiar efecto cognitivo de las listas residía en dos aspectos: el potencial informativo acerca de lugares, instrucciones y límites, y el proceso que se llevaba a cabo para ordenar los ítems por nombre, sonido inicial, categoría o cualquier otro criterio. Las listas y los inventarios fueron entonces herramientas indispensables para la circulación del conocimiento en su forma conceptual tanto como material y sus cualidades sintéticas permitieron la transmisión de información y la manipulación del saber que contenían estabilizado en palabras. Sin embargo, esas palabras no eran suficientes para construir un conocimiento profundo en el contexto de un gabinete de historia natural, y la presencia de dibujos, tanto como de los objetos mismos eran fundamentales para completar el proceso de significación de la naturaleza. De ese modo, en el contexto del coleccionismo natural las tecnologías de papel quintaesenciaron la comunicación entre la Corona española y sus posesiones, además de haber sido útiles para ordenar el mundo y configurar un entorno material que permitía generar, estabilizar e incluso, modificar el conocimiento ${ }^{43}$. Los inventarios, los índices e incluso los dibujos fueron, como podemos ver actualmente, la única forma de preservar efectivamente las colecciones de animales que, después de tres siglos, existen aún como colecciones de papel.

3 Sobre el Real Gabinete se han escrito muchos textos en España y éste ha sido motivo de varios estudios como referente de la ciencia española ilustrada. Los principales autores que se consultan para este tema son Solano (1871), Barreiro (1992), Calatayud (1986, 1987, 1988) y Mieg (2009). Aunque Solano fue de los primeros autores en escribir acerca de la historia del Gabinete, Barreiro es uno de los más importantes al menos para el siglo veinte -la primera edición de su texto es de 1936-, Calatayud realizó varias biografías de Pedro Franco Dávila y sistematizó los fondos documentales del Museo Nacional de Ciencias Naturales de Madrid, producidos entre 1771 y 1845, mientras que Mieg realizó una descripción exhaustiva del Real Gabinete a principios del siglo diecinueve. El texto más extenso y reciente sobre este tema es el realizado por Villena, et. al. (2009), en él los auto- 
res recogen la biografía de Dávila y la suman a la historia del Gabinete hasta inicios del siglo diecinueve haciendo especial énfasis en las colecciones marinas. Con una visión más crítica están también los textos de Juan Pimentel (2003a y 2003b), Helen Cowie (2011a) y Camilla Ruud (2012).

4 Staffan Müller-Wille e Isabelle Charmantier, reconocen en las listas su capacidad de presentar y preservar el conocimiento de forma sinóptica, concisa, estructurada y abierta como los atributos fundamentales que les permiten ser reconocidos como herramientas teóricas (Müller-Wille y Charmantier 2012, p.744).

5 Las listas han sido analizadas como objetos de arte, historia y ciencia. Por citar sólo algunos ejemplos cito los textos de Kirwin (2010), Eco (2009), el monográfico introductorio a la revista Isis hecho por Delbourgo y Müller-Wille (2012), o el seminario llevado a cabo en Madrid en 2013 Por una historia de las listas en la época moderna (siglos XV-XIX), programa disponible en: http://www.casadevelazquez.org/es/investigacion/novedad/por-una-historia-de-las-listas-en-la-epocamoderna-siglos-xv-xix/ [consultado el 28/05/2014]

6 Sobre las prácticas de escritura en el coleccionismo y la ciencia ver Johns (1996), Lafuente y Pimentel (2002), Pardo (2010) y Pugliano (2012) entre otros.

7 Sobre la iniciativa de Ulloa y el Gabinete de Minas ver: Calatayud (1986), Corella (1987) y Losada y Varela (1995). Sobre la respuesta novohispana a esta solicitud ver: Constantino (2011). El original de la solicitud enviada al gobierno novohispano se encuentra en: Archivo General de la Nación, México (AGN). Instituciones Coloniales, Gobierno Virreinal, Reales Cédulas Originales, vol. 177. Exp. 64.

8 AGN. Gobierno Virreinal, Correspondencia de Virreyes (036), vol. 189 , fojas $165-166$.

9 AGN. Gobierno Virreinal, Reales Cédulas Originales, vol. 185, exp. 73.

10 AGN. Gobierno Virreinal, Indiferente Virreinal, caja 1959, exp. 006

11 No obstante que la idea de Antonio de Ulloa se había adaptado con facilidad a las empresas monárquicas que en su momento se estaban llevando a cabo para recuperar la historia y el conocimiento antiguo hispano, la iniciativa de establecer un gabinete Real no prosperó en su momento como tal. Sin embargo, del proyecto inicial de Ulloa se desprendió en 1753 la Real Casa de la Geografía y Gabinete de Historia Natural. Ambos se mantuvieron en pie con algunos tropiezos durante trece años, hasta que en 1766, después de varios intentos por conservarlo, sus colecciones fueron repartidas entre el Protomedicato y la Corona (Barreiro, 1992, p. 57-58). No obstante lo efímero de su existencia, ese primer intento por establecer una colección favoreció a la larga la conformación de otros gabinetes de dimensiones menores. El "Gabinete del Príncipe" (Calatayud, 1988, p. 50) fue uno de ellos: era una sala adornada con armarios y cristales, des- tinada a guardar y exhibir ejemplares naturales, para apoyar y complementar la educación e instrucción del heredero de la Corona, Carlos IV (Barreiro, 1992, p. 59). El gabinete reflejaba el interés monárquico por incluirse en la tradición coleccionista propia de los gobernantes y hombres sabios de la época. Sin embargo era muy pequeño y no tenía acceso público. No era suficiente para mostrar toda la riqueza que había en el territorio, y eso era algo que debía solucionarse.

12 Instrucción hecha de Orden del Rey N.S. para que los Virreyes, Gobernadores, Corregidores, Alcaldes Mayores e Intendentes de Provincias de todos los dominios de S. M. puedan hacer escoger, preparar y enviar a Madrid, todas las producciones curiosas de la Naturaleza que se encontraren en tierras y pueblos de sus distritos, a fin de que se coloquen en el Real Gabinete de Historia que S.M. ha establecido en esta corte para beneficio e instrucción pública.

Sobre este documento, necesario para entender el proceso del coleccionismo de historia natural en España se ha escrito ya con anterioridad. El texto completo de la Instrucción de Dávila puede consultarse en: Lemoine (1961), y Mercurio Histórico y Político (Mayo, 1776). Sobre la Instrucción y su relación con las prácticas de coleccionismo de corresponsales y expedicionarios ver: Constantino (2011) y Cowie (2011b y 2011c). El recuento de cómo surgió este documento, su estrategia de difusión, su carácter enciclopédico y su vínculo con otras instrucciones monárquicas de coleccionismo aparece en Constantino y Pimentel (2014). El documento impreso que llegó a Nueva España se encuentra en: AGN. Instituciones Coloniales, Indiferente Virreinal, Impresos Oficiales, vol. 10, exp. 8.

13 Hemeroteca Digital. Biblioteca Nacional de España. Mercurio Histórico y Político (Mayo, 1776): 92-133, http://hemerotecadigital.bne.es/issue.vm?id=0012206113\&page=94\&sea rch=mercurio\&lang=es [consultado el 15/03/2014].

14 El texto de Constantino y Lafuente (2012) explica en detalle la relevancia que los procesos de conservación tenían para llevar a cabo una práctica coleccionista exitosa. Ahí se muestran los procesos indicados por Dávila en la Instrucción, así como los posibles actores que intervinieron en el proceso y las respuestas alternativas que los naturalistas novohispanos proponían a los métodos europeos.

15 AGN. Instituciones Coloniales, Indiferente Virreinal, Impresos Oficiales, vol. 10, exp. 8.

16 AGN. Instituciones Coloniales, Indiferente Virreinal, Impresos Oficiales, vol. 10, exp. 8.

17 La nota al pie dice así: "Siendo nuestro intento nombrar solamente con toda brevedad las producciones más conocidas, no observaremos el método de los Autores, ni la nomenclatura conocida en Europa, e ignorada ciertamente de muchos en América, por evitar a cada paso definiciones que serían indispensables para la inteligencia de la materia." AGN. Instituciones Coloniales, Indiferente Virreinal, Impresos Oficiales, vol. 10, exp. 8. 
18 AGN. Instituciones Coloniales, Indiferente Virreinal, Impresos Oficiales, vol. 10, exp. 8.

19 Para este caso particular podemos pensar, por ejemplo, que el perro volador podría haber sido en realidad un murciélago de grandes dimensiones, similar a los asiáticos que aún hoy en día son conocidos en occidente como zorros voladores.

20 Dado que este artículo habla específicamente del corpus documental de las colecciones no entraré en detalles sobre los procesos y el trabajo que implicaba la práctica de recolección, conservación y naturalización de los ejemplares coleccionados. Sin embargo, sobre esto puede leerse en Constantino y Lafuente (2012) y en Constantino (2013, p. 165-224).

21 Sobre la vida y obra de Vilella ver: Azcárate (1987) y Villena, M., et al. (2009, p. 695).

22 AMNCN (Archivo del Museo Nacional de Ciencias Naturales). Catálogo de documentos del Real Gabinete de Historia Natural (1752-1786). Ref. 504.

23 AMNCN. Catálogo de documentos del Real Gabinete de Historia Natural (1752-1786). Ref. 504.

24 AMNCN. Catálogo de documentos del Real Gabinete de Historia Natural (1752-1786). Ref. 504.

25 Un problema similar lo tenía en el virreinato de La Plata el corresponsal Félix de Azara, quien cazaba a punta de escopeta las aves que quería remitir al Gabinete Real sin tener mayor cuidado de no dañarlas o de conservarlas lo mejor posible, lo cual repercutió en que Dávila no aceptara la mayor parte de sus remisiones por no cumplir con los estándares mínimos de sus requisitos. Ver Figueroa (2011).

26 Los métodos de conservación y preparación se dividían en secos y húmedos. Entre los primeros se encontraba la deshidratación de las pieles por medio del salado; el rellenado de las mismas con mezclas de sal, especias de olor fuerte, hierbas aromáticas y algunos venenos; también mezclas de alumbre, pimienta, salitre -saltpetre-, polvo de tabaco - ground tobacco snuff-, clavo, alcanfor, azufre, almizcle y mercurio -corrosive sublimate- y polvos de otras plantas como lavanda, albahaca, laurel, salvia, tomillo o ajenjo para tratar de mantener lejos a los bichos (Pequignot, 2002, Constantino y Lafuente, 2012, Constantino, 2013). Mientras que los métodos húmedos consistían básicamente en sumergir al animal en espíritu de vino o aguarrás dentro de frascos herméticos. La decisión de usar unos u otros métodos dependían principalmente del tamaño de los ejemplares. Los barnices a los que se refería Vilella estaban hechos normalmente con alcanfor, trementina cruda y espíritu de trementina o aguarrás y servían para protegerlos de las polillas una vez disecados y naturalizados.

27 AMNCN. Catálogo de documentos del Real Gabinete de Historia Natural (1752-1786). Ref. 504

28 AMNCN. Catálogo de documentos del Real Gabinete de Historia Natural (1752-1786). Ref. 792.
29 Hay una imprecisión en las fechas de este documento porque el borrador está fechado el 17 de julio de 1784 y dice que los cajones se enviaron por medio del Ministro de Indias, José de Gálvez. El inventario hecho por el copiador de cartas No. 18, tiene el mismo documento fechado el 18 de julio de 1783, no menciona a José de Gálvez sino al virrey Matías de Gálvez y atribuye la recolección a José Ibargoyen. Ambos documentos están clasificados con la misma referencia en el Archivo del Museo de Ciencias Naturales de Madrid, y aunque comparten algunas cosas en el listado, el inventario hecho por el copiador es mucho más extenso y descriptivo. AMNCN. Catálogo de documentos del Real Gabinete de Historia Natural (1752-1786). Ref. 792. Por otro lado, en el Archivo General de la Nación (AGN) aparece un documento con fecha 21 de junio de 1784 donde desde el Real Gabinete de Historia Natural de Madrid se acusa de recibido y se agradece a Ibargoyen la remisión de producciones naturales. AGN. Instituciones Coloniales. Gobierno Virreinal. Reales Cédulas y Duplicados. Reales Cédulas Originales, Vol. 128, exp. 151.

30 AMNCN. Catálogo de documentos del Real Gabinete de Historia Natural (1752-1786). Ref. 792.

31 AMNCN. Catálogo de documentos del Real Gabinete de Historia Natural (1752-1786). Ref. 792.

32 AMNCN. Catálogo de documentos del Real Gabinete de Historia Natural (1752-1786). Ref. 792.

33 AMNCN. Catálogo de documentos del Real Gabinete de Historia Natural (1752-1786). Ref. 504.

34 Sobre la Expedición Botánica a Nueva España pueden leerse los textos de Arias (1968), Taracena (1983), Lozoya (1984), Sánchez, Puig-Samper y Sota (1987), San Pío y Puig-samper (2000), Maldonado (2001), Labastida, et.al (coords.) (2010). El inventario correspondiente a su primera remesa se encuentra en: AMNCN. Catálogo de las expediciones y viajes científicos españoles, siglos XVIII y XIX. Expedición a Nueva España. Ref. 491.

35 Sobre este cirujano riojano y su labor como expedicionario y naturalista han escrito Bernabeu (1994), Maldonado (1997), y Constantino y Lafuente (2012).

36 AMNCN. Catálogo de las expediciones y viajes científicos españoles. Siglos XVIII y XIX. Expedición a Nueva España. Ref. 493.

37 AMNCN. Catálogo de las expediciones y viajes científicos españoles, siglos XVIII y XIX. Expedición a Nueva España. Ref. 505.

38 Para conocer los antecedentes y repercusiones de esta disputa, ver: Constantino (2013, pp. 38-102).

39 AGN D257. Historia. Vol. 527. Exp. 14. Carta de Sessé a Longinos. 1 을 de abril de 1790 .

40 AGN D257. Historia. Vol. 527. Exp. 14. Carta de Sessé a Revillagigedo. 6 de abril de 1790. 
41 AMNCN. Catálogo de las expediciones y viajes científicos españoles, siglos XVIII y XIX. Expedición a Nueva España. Ref. 505.

42 Estos eran los elementos más susceptibles de verse afectados por la disecación, el estofado o la inmersión en espíritu de vino. Recordemos el caso del ave del paraíso en el que la falta de conservación de sus patas llevó a los naturalistas

\section{BIBLIOGRAFÍA}

Arias Divito, Juan Carlos (1968), La expediciones cientificas españolas durante el siglo XVIII. Expedición botánica de Nueva España. Madrid, Cultura Hispánica.

Azcárate, Isabel (1987), “Cristóbal Vilella: un naturalista en la academia", Academia: Boletín de la Real academia de Bellas Artes de San Fernando, 64, pp. 417-432.

Barreiro, Agustín (1992), El Museo Nacional de Ciencias Naturales (1771-1935). Madrid, Museo Nacional de Ciencias Naturales (MNCN), Doce Calles.

Bernabéu Albert, Salvador (1994), Diario de las expediciones a las Californias de José Longinos. Aranjuez, Doce Calles.

Calatayud Arinero, María de los Ángeles (1986), "Antecedentes y creación del Real Gabinete de Historia Natural de Madrid", Arbor, 123 (482), pp. 9-33.

Calatayud Arinero, María de los Ángeles (comp.) (1987), Catálogo de documentos del Real Gabinete de Historia Natural, 1752-1786: Fondos del Archivo del Museo Nacional de Ciencias Naturales. Madrid, Consejo Superior de Investigaciones Cientificas (CSIC), MNCN.

Calatayud Arinero, María de los Ángeles (1988), Pedro Franco Dávila: primer director del Real Gabinete de Historia Natural fundado por Carlos III. Madrid, CSIC, MNCN.

Constantino, María Eugenia (2011), "Instrucciones y prácticas para coleccionar naturaleza en Nueva España, 1787-1803", Cuicuilco, 18 (52), pp. 173-189.

Constantino, María Eugenia y Antonio Lafuente (2012), "The Hidden Logistics of Longinos's Novohispanic Cabinet", Nuncius, 27 (2), pp. 348-370

Constantino, María Eugenia (2013), Prácticas de coleccionismo y construcción del conocimiento. Colecciones de naturaleza novohispana para el Real Gabinete de Historia Natural de Madrid. 1752-1803, Tesis, Laura Cházaro y Eugenia Roldán (dirs.). México, inédito.

Constantino, María Eugenia y Juan Pimentel (2014), "Como inventariar el (Nuevo) Mundo". En: Cházaro, Laura; Miruna Achim y Nuria Valverde (eds.), Circulación de saberes: Instrumentos y colecciones en la historia. México, CINVESTAV, UAM, En prensa. del siglo XVI y XVII a pensar que en la naturaleza carecía de ellas. Sobre este caso particular ver: Marcaida (2011). Sobre los problemas de conservación en las remesas novohispanas para el Real Gabinete ver: Constantino y Lafuente (2012).

43 Esto según las características que Hess y Mendelsson (2010) exponen acerca de las tecnologías de papel.

Corella Suárez, Pilar (1987), "La Real Casa de Geografía de la Corte y el comercio ultramarino durante el siglo XVIII", Anales del Instituto de Estudios Madrileños, 24, pp. 217-236.

Cowie, Helen (2011a), Conquering Nature in Spain and its Empire 1750-1850. Manchester, University of Manchester Press.

Cowie, Helen (2011b), "Sloth bones and anteater tongues: Collecting American nature in the Hispanic World (17501808)", Atlantic Studies: Literary, Cultural and Historical Perspectives, 8 (1), pp. 5-27.

Cowie, Helen (2011c), "A Creole in Paris and a Spaniard in Paraguay: Geographies of Natural History in the Hispanic World (1750-1808)", Journal of Latin American Geography, 10 (1), pp. $175-197$.

Delbourgo, James y Staffan Müller-Wille (2012), "Listmania. How lists can open up fresh possibilities for research in the history of science", Isis, 103 (4), pp. 710-715, p. 710.

Eco, Umberto (2009), El vertigo de las listas. Madrid, Random House Mondadori.

Figueroa, Marcelo Fabián (2011), “En los márgenes del Imperio Español y de la Historia natural: Félix de Azara colector (1787-1789)", Prohistoria, 15, pp. 00-00, [en línea], disponible en: http://www.scielo.org.ar/scielo.php?script=sci_ arttext\&pid=S1851-95042011000100001\&lng=es\&nrm=iso [Consultado el 10/10/14].

Hess, Volker and Andrew Mendelsohn (2010), "Case and series: medical knowledge and paper technology, 1600-1900", History of Science, 48 (3-4), pp. 287-314, p. 287.

Johns, Adrian (1996), "Natural History as Print Culture". En: Jardine, N.; J. A. Secord and E. C. Spary (eds.), Cultures of Natural History, Cambridge, Cambridge University Press, pp. 106-124.

Kirwin, Liza (2010), Lists: To-dos, Illustrated Inventories, Collected Thoughts, and Other Artist's enumerations from the Smithsonian's Archives of American Art. New York, Princeton Architectural Press.

Labastida, J.; E. Morales; J. L. Godínez; M. H. Flores; F. Chiang; A. Vargas y M.E. Montemayor (coords.) (2010), José Mariano Mociño y Martín de Sessé: La Real Expedición Botánica a Nueva España, México, UNAM y Siglo XXI Editores. 
Lafuente, Antonio y Juan Pimentel (2002), “La construcción de un espacio público para la ciencia: escrituras y escenarios en la ilustración española”. En: Peset Reig, José Luis (dir.), Historia de la ciencia y de la técnica en la Corona de Castilla. Siglo XVIII, Madrid, Junta de Castilla y León, Consejería de Educación y Cultura, pp. 111-156.

Lemoine Villicaña, Ernesto (1961), Instrucción para aumentar las colecciones del Gabinete de Historia Natural de Madrid, 1776. México, Archivo General de la Nación.

Losada, M. y Varela, C. (eds.) (1995), I/ Centenario de Don Antonio de Ulloa. Sevilla, Escuela de Estudios Hispanoamericanos, CSIC, Archivo General de Indias.

Lozoya, Xavier (1984), Plantas y luces en México. Barcelona, Ed. del Serbal.

Maldonado Polo, J. Luis (1997), De California a El Petén. El naturalista riojano José Longinos Martínez en Nueva España. Logroño, Instituto de Estudios Riojanos.

Maldonado Polo, J. Luis (2001), Las Huellas de la Razón. Madrid, CSIC.

Marcaida López, José Ramón (2011), Juan Eusebio Nieremberg y la ciencia del Barroco. Conocimiento y representación de la naturaleza en la España del siglo XVII, Dr. Juan Pimentel Igea (dir.), Tesis. Madrid, Universidad Autónoma de Madrid, Inédito.

Mieg, Juan (2009), [e.o.1818], Paseo por el Gabinete de Historia Natural de Madrid. Valladolid, Maxtor.

Müller-Wille, Staffan e Isabelle Charmantier (2012), "Lists as Research Technologies”, Isis, 103 (4), pp. 743-752, p. 744.

Pardo Tomás, José (2010), “Escrito en la rebotica. Coleccionismo naturalista y prácticas de escritura en el gabinete de curiosidades de la familia Salvador. Barcelona, 1626-1857", Cultura Escrita y Sociedad, 10, pp. 18-52.

Pardo Tomás, José (2012), “La huella de Francisco Hernández en las relaciones geográficas de Nueva España”, Crónicas, 22, pp. 17-18.
Pequignot (2002), Histoire de la Taxidermie en France (17291928). Etude des facteurs de ses évolutions techniques et conceptuelles, et ses relations à la mise en exposition du spécimen naturalisé, Tesis. Paris, Muséum National d'Histoire Naturelle, Inédito.

Pimentel Igea, Juan (2003a), Testigos del mundo: ciencia, literatura y viajes en la ilustración. Madrid, Marcial Pons, pp. 25-70, pp.149-178.

Pimentel Igea, Juan (2003b), "La naturaleza representada: el Gabinete de maravillas de Franco Dávila". En: Bustamante, Jesús y Mónica Quijada (eds.), Élites intelectuales y modelos colectivos. Mundo Ibérico (siglos XVI-XIX), Madrid, CSIC, pp. 131-154.

Pugliano, Valentina (2012), "Specimen Lists. Artisanal Writing or Natural Historical Paperwork?", Isis, 103 (4), pp. 716-726.

Ruud, Camila (2012), Doing Museum Objects in late EghteehthCentury Madrid, Tesis. Universidad de Oslo, Oslo, Inédito.

Sánchez, Belén; Miguel Ángel Puig-Samper y José de la Sota (eds.) (1987), La Real Expedición Botánica a Nueva España. Madrid, Real Jardín Botánico y Ediciones Quinto Centenario.

San Pío, María Pilar y Miguel Ángel Puig-Samper (2000), El Águila y el nopal. La expedición de Sessé y Mociño a Nueva España. Barcelona, Lunwerg.

Schaffer, Simon (2011), Trabajos de cristal. Ensayos de historia de la ciencia, 1650-1900. Madrid, Marcial Pons, p. 285.

Solano y Eulate, José María (1871), Guía del Gabinete de Historia Natural. Madrid.

Villena, M.; J.S. Almazán; J. Muñoz y F. Yagüe (2009), El gabinete perdido. Pedro Franco Dávila y la Historia Natural del siglo de las luces. Madrid, CSIC.

Taracena Arriola, Arturo (1983), La expedición botánica al reino de Guatemala. Guatemala, Editorial Universitaria. 